\title{
Assessing the effect of TIG alternating current time cycle on aluminium wire + arc additive manufacture
}

\begin{abstract}
:
The effect of electrode positive time cycle (\% EP) of the alternating current TIG process has been investigated for aluminium wire + arc additive manufacture of linear walls. The study considered the effect on oxide removal, linear wall dimensions, microstructure, mechanical properties as well as the effect on electrode wear. The results showed that the effective wall width was minimum at $20 \% \mathrm{EP}$ with a corresponding maximum in layer height. It was also observed that increasing the \% EP increased the electrode wear rate, which in turn affected the arc stability. Microstructure analysis showed a noticeable increase in the grain size for higher \% EP. The study also showed that \% EP had no significant effect on mechanical properties. From a heat input analysis, a direct correlation was observed between the arc voltage and the \% EP. The study also indicated that there could be other contributing factors to wall dimensions. For aluminium wire + arc additive manufacture of linear walls, minimum cleaning ranged between $10 \% \mathrm{EP}$ and 20 $\%$ EP.
\end{abstract}

Keywords: ACTIG; electrode positive; WAAM linear wall; aluminium; equiaxed grains.

\section{Introduction}

Wire + arc additive manufacture (WAAM) is a very promising process for manufacture of parts and components to be produced to near net shape at a reduced cost with shorter lead times compared to machining from solid material $[1,2]$. This will minimise the increasing demands for parts to be produced by worldwide market mainly the aerospace and defence industries [3]. The WAAM process incorporates arc welding processes such as tungsten inert gas (TIG), plasma transfer arc (PTA), metal inert gas (MIG) and cold metal transfer (CMT) which are used to melt and deposit wire in a layer by layer fashion $[1,2,4,5]$.

Aluminium is a material of great interest due to its low weight to strength ratio [6]. However, the oxide film $\left(\mathrm{Al}_{2} \mathrm{O}_{3}\right)$ has a high fusion temperature. This forms on the surface of aluminium which makes it challenging during application of welding processes. Therefore, the oxide film needs to be removed to ensure good fusion and low porosity [6-8]. Current studies have found that using CMT pulse advance process for aluminium WAAM can be beneficial [7,9-11]. However, the CMT process is limited by the inability to vary the current independently of the wire feed speed (WFS). As a result of this, certain desirable weld bead geometries such as flat shaped beads to produce parts to near net shape may be difficult to achieve. Conversely, TIG and PTA processes have been found to offer better control of bead 
geometry due to the flexibility of controlling the process parameters, that is current and WFS, independently $[2,4]$.

In aluminium welding, the alternating current TIG (ACTIG) process has been used because of its ability to allow setting of the proportions of electrode positive (\% EP) to negative (\% EN) time cycle to enhance oxide removal and fusion effect $[8,12,13]$. This is possible because the \% EP part of the AC cycle can effectively remove aluminium oxides through the mechanism known as the cleaning effect $[6,14]$. The mechanism involves the generation of anions from the arc plasma which are directed towards the aluminium base metal (cathode). The impact energy of the anions results in breaking the bonds between the oxides prior to their removal.

The fusion behaviour of variable polarity ACTIG welding of aluminium has been investigated to show that increasing \% EP of the AC cycle increases weld bead penetration and width $[12,15]$. These findings however oppose other literature which indicated that maximum penetration and cleaning are only possible when more than $50 \%$ of the AC time cycle is spent on \% EN and \% EP respectively [16]. Yarmuch and Pepin [8] explained that the increase in fusion in the case of \% EP results from the nature of the cold cathode field emision of electrons which contributes to the additional base metal melting. ACTIG has been used in aluminium WAAM to show the possibility of producing WAAM parts such as cone and linear wall structures $[17,18]$. However, the effect of alternating current time cycle on AI WAAM fusion and oxide removal is still unidentified. This study therefore investigates the effect of ACTIG on AI WAAM by assessing the effect of alternating current time cycle on cleaning and linear wall dimensions (wall width and layer height). In addition, the effect on mechanical properties and microstructure has also been investigated.

\section{Experimental setup and procedures}

\subsection{Materials}

In this experiment, aluminium 5556 wire was deposited on 6082-T6 aluminium substrate. The composition of the materials is shown in Table 1. The substrates used were machined in the form of dummy walls of dimension $160 \mathrm{~mm} \times 10 \mathrm{~mm} \times 20 \mathrm{~mm}$ and were washed and cleaned using ethanol to remove dirt and grease. Prior to welding, substrates were subsequently linished mechanically and then finally degreased with acetone.

Table 1: Material Composition in wt\%

\begin{tabular}{|c|c|c|c|c|c|c|c|c|c|c|c|}
\hline \multirow[t]{2}{*}{ Material } & \multicolumn{11}{|c|}{ Composition } \\
\hline & $\mathrm{Al}$ & $\mathrm{Si}$ & $\mathrm{Mg}$ & $\mathrm{Cr}$ & $\mathrm{Mn}$ & $\mathrm{Ti}$ & $\mathrm{Cu}$ & $\mathrm{Zn}$ & $\mathrm{Fe}$ & $\mathrm{Zr}$ & Other \\
\hline $\begin{array}{l}\text { Al } \\
5556\end{array}$ & Bal & 0.20 & $\begin{array}{l}4.7- \\
5.5\end{array}$ & $\begin{array}{l}0.05- \\
0.20\end{array}$ & $\begin{array}{l}0.50- \\
1.0\end{array}$ & $\begin{array}{l}0.05- \\
0.20\end{array}$ & 0.10 & 0.25 & 0.40 & - & 0.15 \\
\hline
\end{tabular}




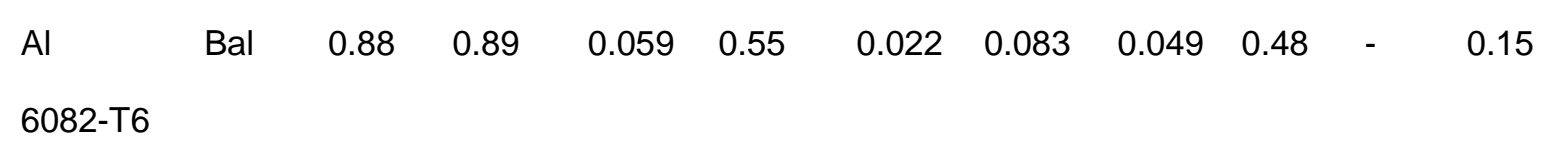

\subsection{Equipment}

The experiments were performed using a Trio 3 axis motion system $\mathrm{CNC}$ with a Migatronic TIG commander 330 AC/DC power source. A multi-strike tungsten electrode of diameter $3.2 \mathrm{~mm}$ was used. This was set to have an arc length of $5 \mathrm{~mm}$ perpendicular to the substrate as illustrated in Figure 1. The wire was fed from the front to align with the centre of the electrode by touching the substrate at an angle of 36 degrees. Argon shielding gas at a flow rate of $15 \mathrm{~L} / \mathrm{min}$ was used as the protective environment. A cooling system placed underneath the substrate was used to cool down the substrate to room temperature between layers.

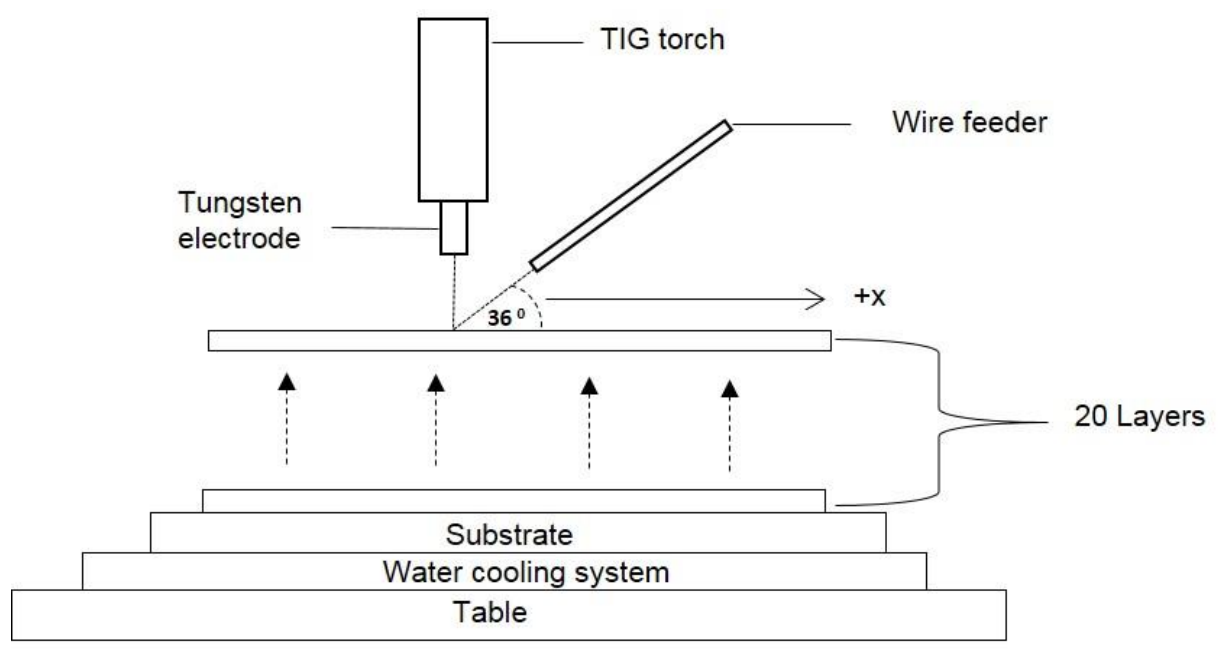

Figure 1: Schematic illustration of TIG WAAM of a 20 - layer wall built on substrate, subsequent layers in the same direction $(+x)$

\subsection{Experimental}

To assess the effect of TIG alternating current time cycle on wire + arc additive manufacture, twenty layer walls were built. These walls had a length of $140 \mathrm{~mm}$ and were built in one direction $(+\mathrm{x})$ as illustrated in Figure 1. The subsequent layer height increments used were the average layer heights of previously deposited layers and were allowed to cool to room temperature prior to deposition of the subsequent layer. A cooling system (set to $20^{\circ} \mathrm{C}$ ) was used to reduce the waiting time after each deposition. The deposition wire feed speed (WFS) was set to $1.6 \mathrm{~m} / \mathrm{min}$ throughout the experiment. To account for the cooling of the substrate for the first four layers, the welding current (I) was varied at a constant travel speed of $0.15 \mathrm{~m} / \mathrm{min}$ as shown in Table 2. Subsequent layers were deposited with TS of $0.3 \mathrm{~m} / \mathrm{min}$ and current of $110 \mathrm{~A}$ at a constant frequency of $50 \mathrm{~Hz}$ whiles the \% EP time cycle was varied at 10 $\%$ EP, $20 \%$ EP, $30 \% E P, 40 \% E P$ and $50 \% E P$. Further experiments were also conducted by varying the frequency at a constant \% EP of $50 \%$ EP. An AMV4000 
equipment was employed to measure the current and voltage. The average heat input $(\mathrm{HI})$ was then calculated using equation (1).

$H I=n(I \times V) / V$

(current $(\mathrm{I})$, voltage $(\mathrm{V})$, travel speed $(\mathrm{v})$, efficiency $(\mathrm{n}=0.6[19])$

Prior to wall building, single layer beads were deposited on a substrate of dimension $200 \mathrm{~mm} \times 200 \mathrm{~mm} \times 6 \mathrm{~mm}$ using layer 1 parameters to assess the effect of \% EP on oxide removal. In addition, the effect of \% EP on electrode wear was measured after deposition with reference to a spot which was made on the electrode prior to deposition.

Table 2: Input process parameters

\begin{tabular}{lll}
\hline Layer Number & Actual I (A) & TS $(\mathrm{m} / \mathrm{min})$ \\
\hline 1 & 192 & 0.15 \\
\hline 2 & 174 & 0.15 \\
\hline 3 & 156 & 0.15 \\
\hline $5-20$ & 138 & 0.15 \\
\hline
\end{tabular}

\subsection{Macrostructure and microstructure analysis}

Linear walls built were sectioned and their bead dimensions were measured using an optical microscope. Prior to macrostructure and microstructure analysis, samples were cold mounted in epoxy and subsequently ground using 240, 600, 1200 and $2500 \mathrm{SiC}$ grit paper. This was then polished to mirror finish using $3 \mu \mathrm{m}$ diamond paste and $1.5 \mu \mathrm{m}$ colloidal silicon suspension. Figure 2 illustrates a schematic of a generic wall cross section showing effective wall width (EWW), total wall width (TWW) and surface waviness (SW). Electron backscattered diffraction (EBSD) was conducted to observe the microstructure. Pore counting was conducted along the middle section (approximately $100 \mathrm{~mm}^{2}$ ) using the optical microscope and the IMAGE J software.

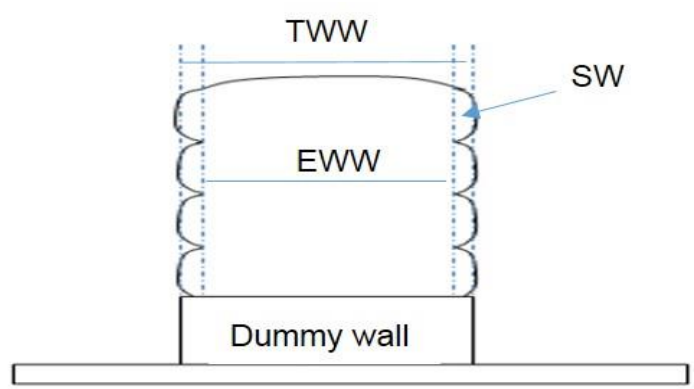

$$
S W=(T W W-E W W) / 2
$$

Figure 2: Schematic of linear wall macrostructure 


\subsection{Hardness and tensile testing}

Hardness measurements were conducted using a micro hardness indenter by applying a load of $200 \mathrm{~g}$ at 10 different points across the test specimens. An average hardness value was calculated in each test. Tensile tests were also conducted in the longitudinal direction using an Instron - 5500R (load cell capacity $=30 \mathrm{KN}$, test speed $=1 \mathrm{~mm} / \mathrm{min}$ ) at room temperature on $20 \%$ and $50 \%$ EP walls built. For this test, 33 layer walls were built on a substrate of dimension $500 \mathrm{~mm} \times 150 \mathrm{~mm} \times 12.7$ $\mathrm{mm}$ and three test specimens were taken in the longitudinal direction from each wall of which the average values were calculated. During wall building, a constant \% EP of $30 \%$ was used in the first four layers (Table 2 ) to account for the cooling of the substrate.

\section{Results}

\subsection{Effect of ACTIG time cycle on width of oxide removal}

Figure $3 a$ and $3 b$ show the effect of \% EP on the width of oxide removal. The results indicate insufficient cleaning effect for $5 \% \mathrm{EP}$ as observed by the dark spots on the deposited layer. It can also be seen that the width of cleaning (white band), Figure $3 a$ increases as \% EP increases between $10 \%$ and $50 \%$ (Figure 3b).
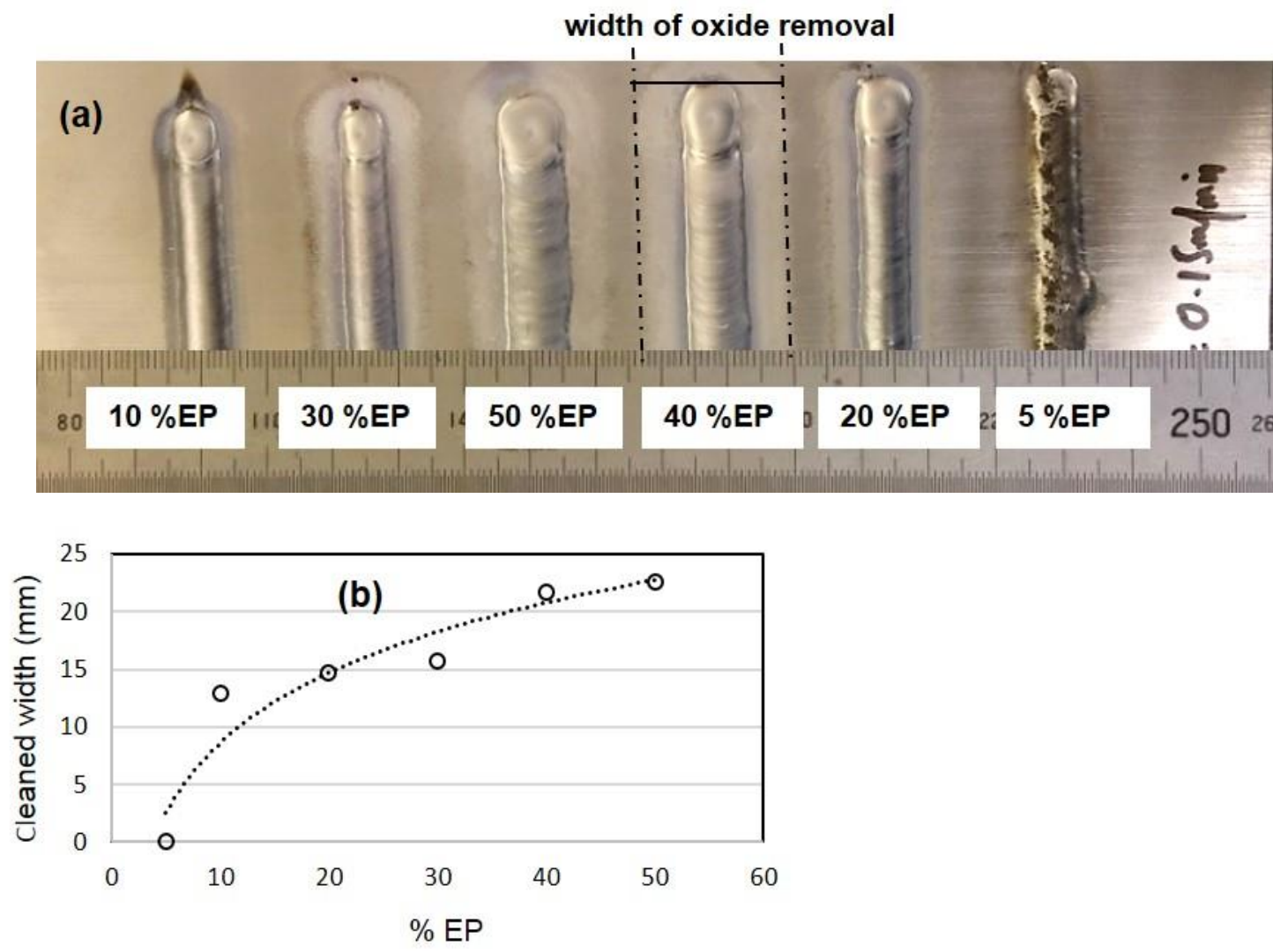

Figure 3: Effect of \% EP on cleaning width: (a) Weld seam nature; (b) Cleaning trend 
Figure $4 a$ and $4 b$ show the effect of \% EP on electrode wear after the first deposited layer. It was observed that increasing \% EP increases the wear of the electrode and this becomes significant for $\% E P>30$.
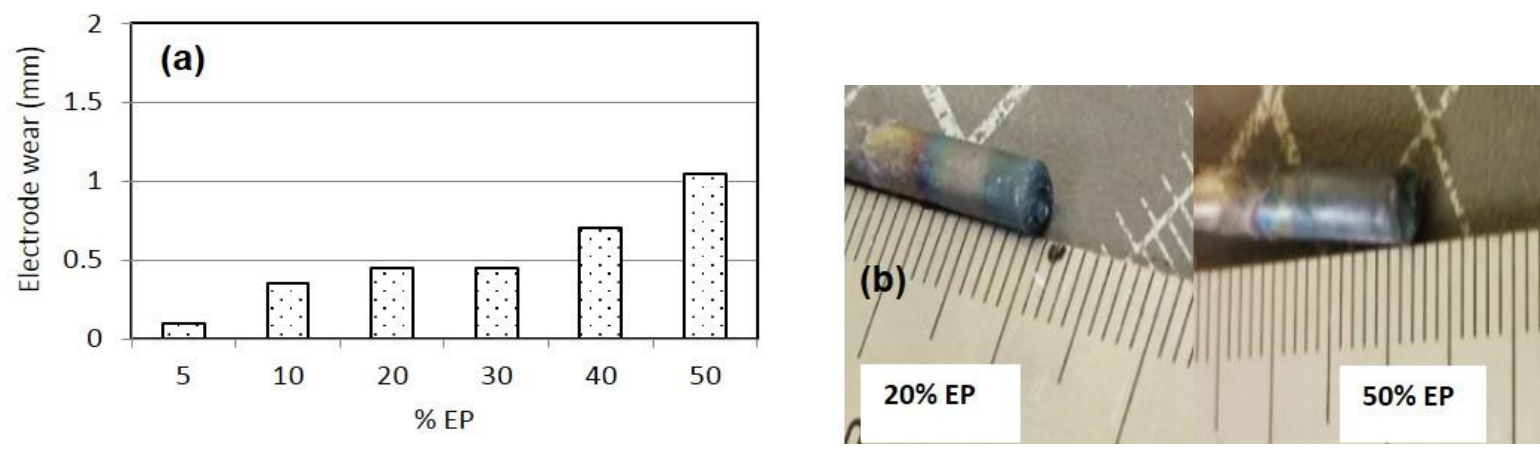

Figure 4: The effect of \% EP on electrode wear

\subsection{Quality of walls}

Figure 5 shows aluminium wire arc additively manufactured linear walls by variable polarity ACTIG process. This shows the physical characteristics of walls built and the parameters used. It can be seen that the cleaning effect was reduced below $20 \% \mathrm{EP}$ as shown by $10 \% E P$ wall built which was slightly darkened in comparison to the other linear walls.

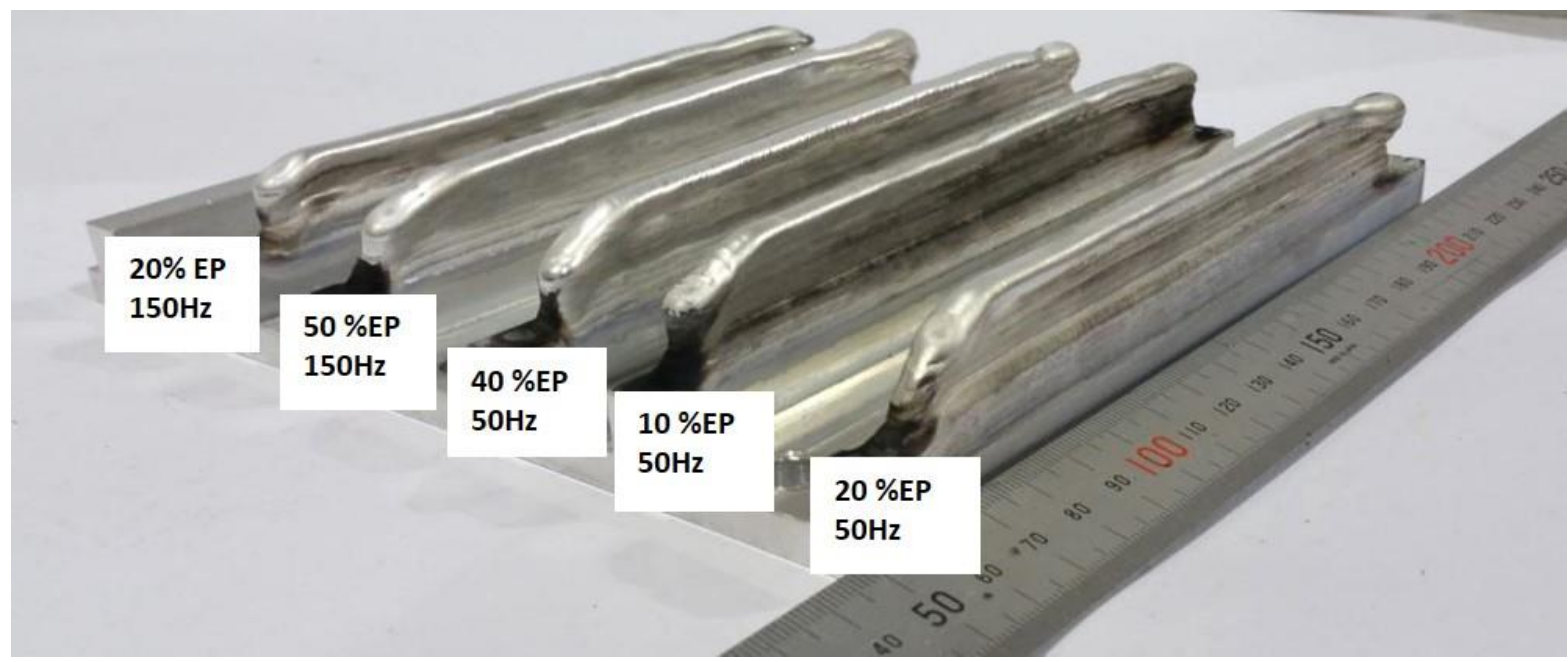

Figure 5: Physical characteristics of WAAM walls built by ACTIG

Figures $6 a, 6 b$ and $6 c$ show the effect of \% EP on the effective wall width (EWW), layer height (LH) and surface waviness (SW) of the linear walls built. It can be seen that the effective wall width is minimum at $20 \% \mathrm{EP}$ with a corresponding maximum in layer height. It can also be seen that surface waviness appears to be approximately constant between $10 \% \mathrm{EP}$ and $40 \% \mathrm{EP}$ with a maximum at $50 \% \mathrm{EP}$. 

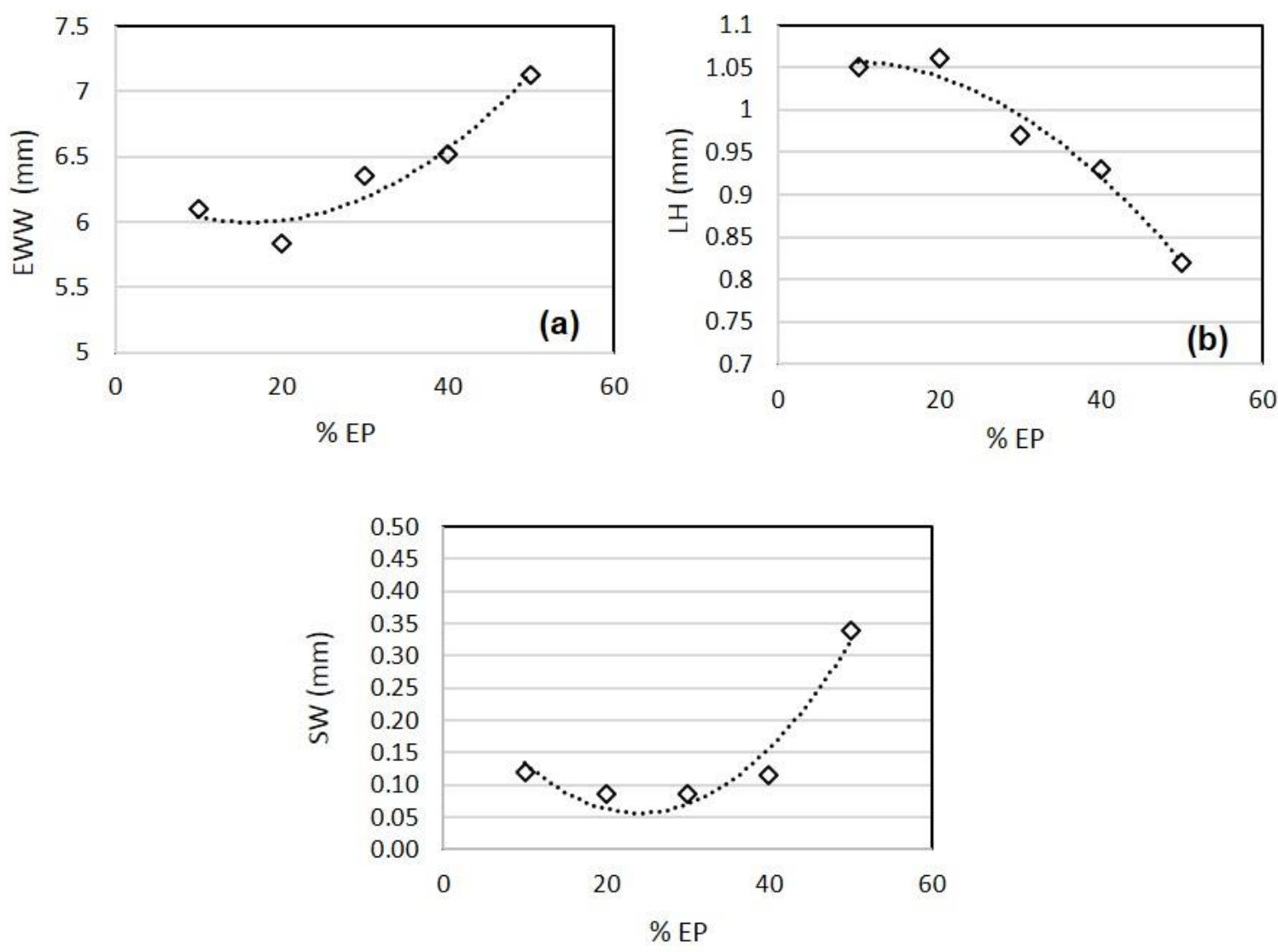

Figure 6: The effect of \% EP time cycle on (a) effective wall width (EWW), (b) layer height (LH) and (c) surface waviness (SW) of aluminium 5556

Figure 7 a shows the effect of frequency at $50 \% \mathrm{EP}$ on EWW and LH for walls built. The results show that increasing the frequency has no significant effect on linear wall dimensions.

Figure $7 \mathrm{~b}$ also shows the effect of \% EP and frequency on the average calculated hardness for AA 5556 WAAM. The results also show no significant effect of \% EP and frequency on the hardness for the WAAM walls produced.
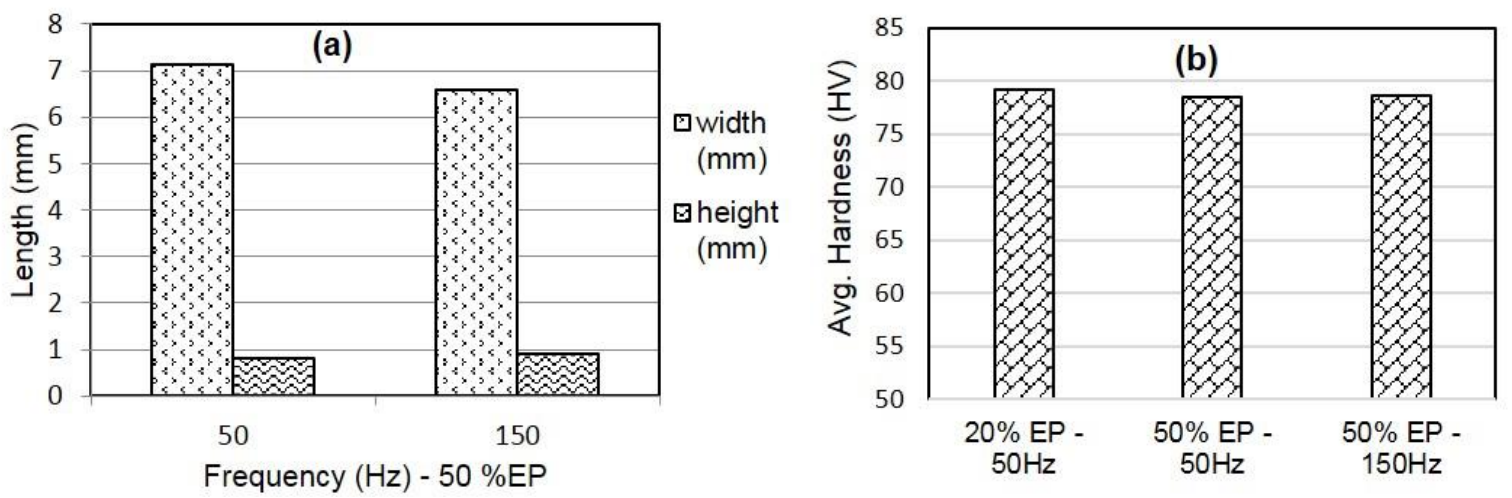

Figure 7: The effect of ACTIG Frequency on (a) wall dimensions and (b) hardness 
Figure $8 \mathrm{a}$ and $8 \mathrm{~b}$ show the effect of \% EP on voltage and heat input for the wire arc additive manufactured walls. It can be seen that the voltage and therefore the heat input are minimum at $20 \% \mathrm{EP}$.
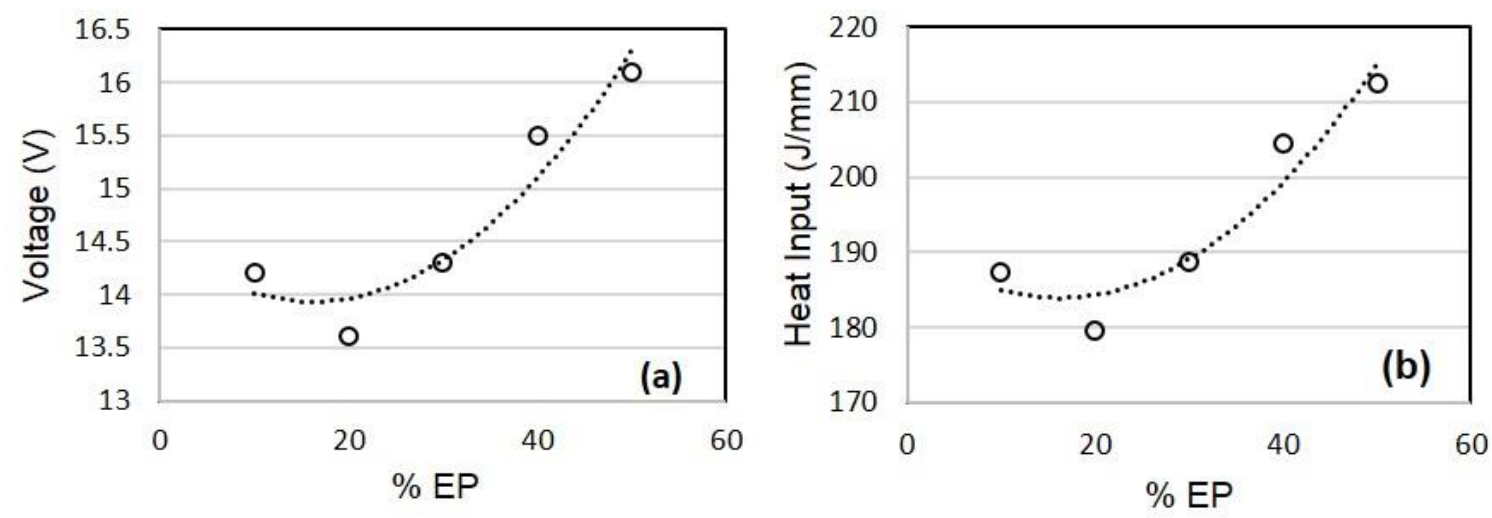

Figure 8: Effect of \% EP on (a) voltage and (b) heat input for linear walls built

Figure 9 shows the effect of $20 \%$ and $50 \%$ EP on microstructure of walls built for a given area. It can be seen that for the same area the grain sizes were coarser in 50 \%EP than $20 \%$ EP.

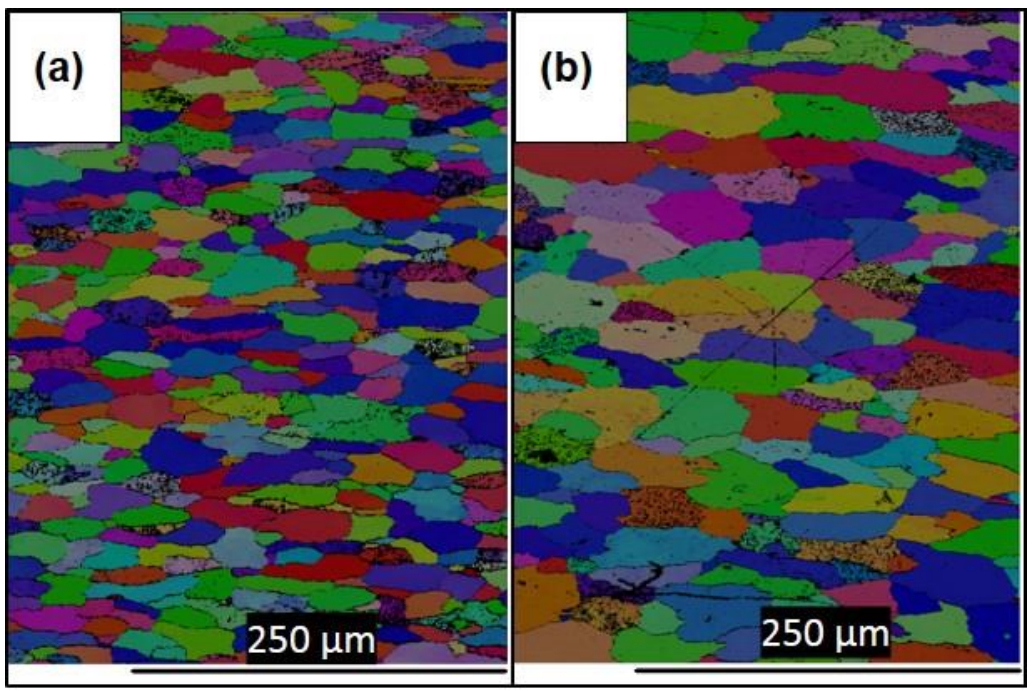

Figure 9: Microstructure of (a) $20 \% \mathrm{EP}$ and (b) $50 \% \mathrm{EP}$ linear walls built

Figure 10 shows the effect of \% EP on porosity for $20 \%$ EP and $50 \%$ EP. It can be seen that for pore sizes ranging between $10-100$ microns, pore sizes and number slightly increased in higher \% EP (50\%EP) than lower \% EP (20\%EP). The results also show that pore sizes and number increases in the initial layers closer to the substrate. 


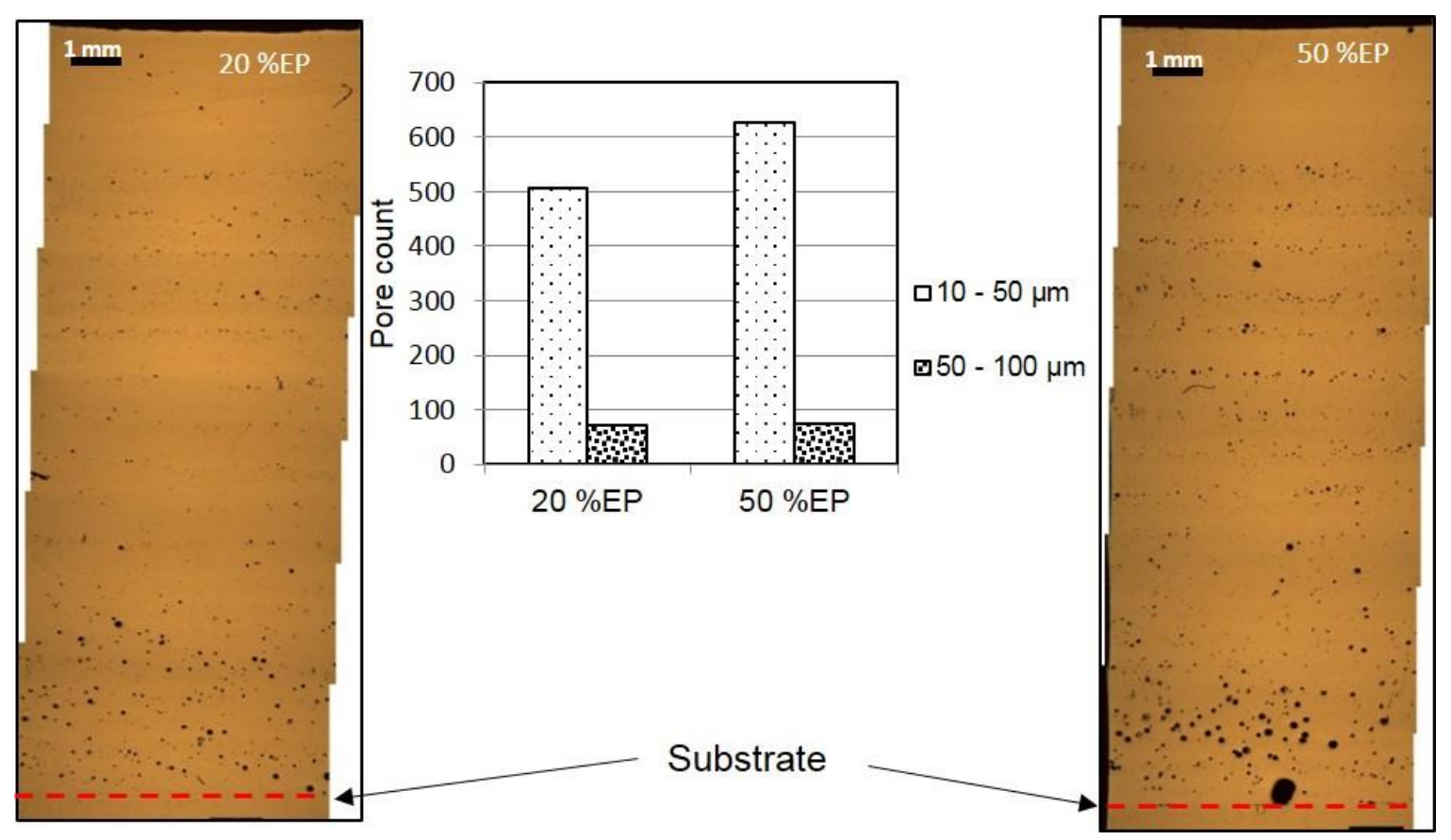

Figure 10: Effect of \% EP on porosity: $20 \%$ EP (left); $50 \% E P$ (right)

Figure 11 shows the effect of \% EP on the ultimate tensile strength (UTS), $0.2 \%$ proof strength (0.2\%PS) and elongation (\%) of $20 \% \mathrm{EP}$ and $50 \% \mathrm{EP}$ walls produced. The results show no significant effect of \% EP on the mechanical properties.

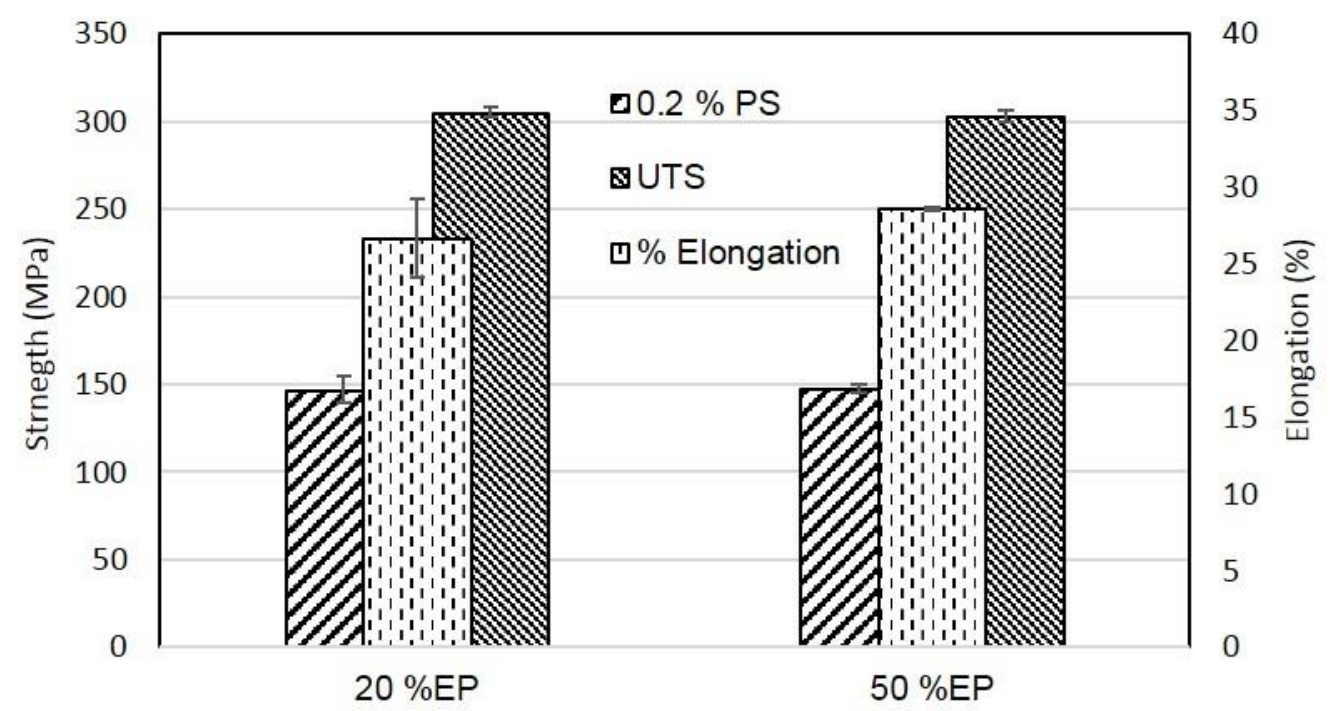

Figure 11: The effect of \%EP on tensile test results

Figure 12 shows the fracture surface of linear walls produced by $20 \% \mathrm{EP}$ and 50 $\%$ EP. It can be seen that both fractured walls are mostly characterised by dimples. 

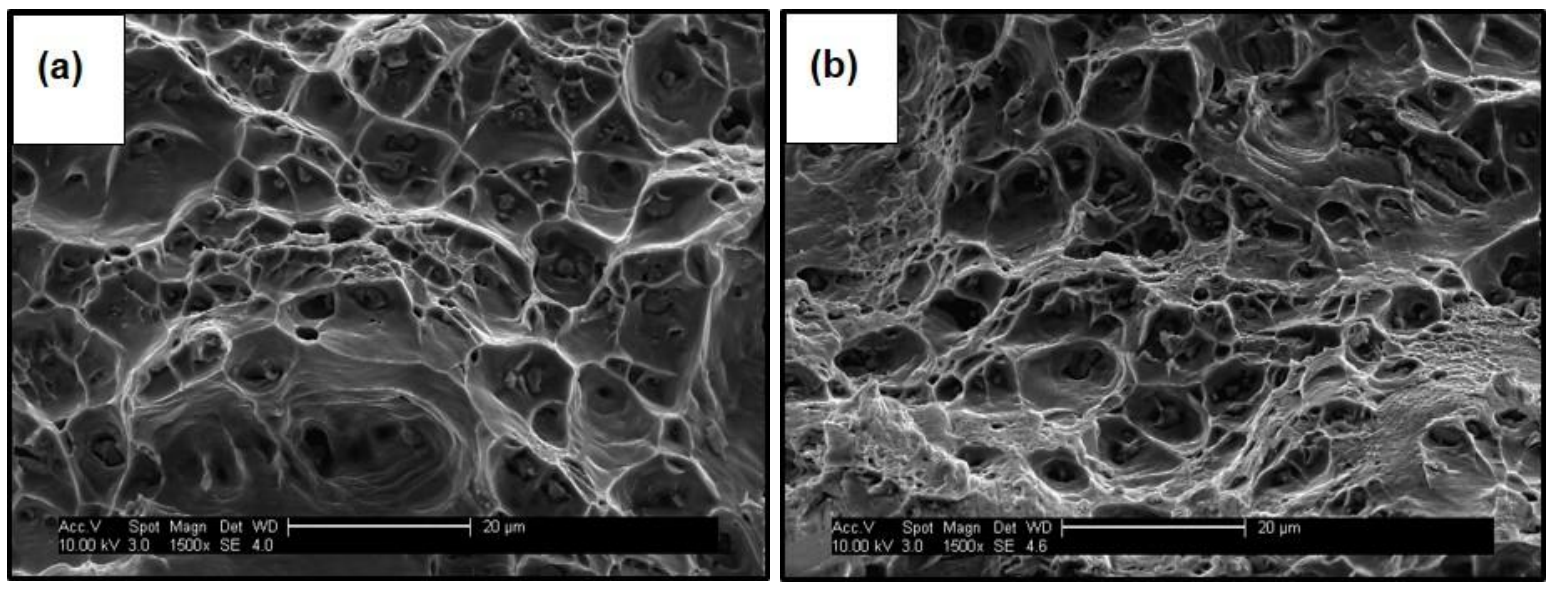

Figure 12: Fracture surface of (a) $20 \% \mathrm{EP}$ and (b) $50 \% \mathrm{EP}$

\section{Discussion}

\subsection{Capability of the process}

The effect of TIG alternating current time cycle on aluminium wire + arc additive manufacture (WAAM) has been investigated for aluminium 5556. It was possible to build linear walls by varying \% EP time cycle between $10 \%$ and $50 \%$ obtaining effective wall width (EWW) and layer height (LH) of $5.8 \mathrm{~mm}$ to $7.1 \mathrm{~mm}$ and $0.8 \mathrm{~mm}$ to $1.1 \mathrm{~mm}$ respectively.

The limiting factor for lower \% EP was based on insufficient oxide removal and an unstable weld bead profile (Figure 3), which confirms previous studies by Cirino and Dutra [12] and Yarmuch and Patchett [8]. In this study, it was found that minimum cleaning ranged between $10 \%$ and $20 \%$ EP. For higher \% EP above $30 \%$, the stability of the arc was affected by the corresponding electrode wear (Figure 4) due to the heating of the electrode. This was apparent since increasing the \% EP increased the wear of the electrode tip correspondingly. From initial studies conducted by Cho et al. [13], it is believed that the melting of the electrode tip affects the absorption of electrons on its surface which in turn makes the arc unstable.

From Figure $6 \mathrm{a}$ and $6 \mathrm{~b}$, it can be seen that the EWW has a minimum at $20 \% \mathrm{EP}$ with corresponding maximum in $\mathrm{LH}$. It has been shown previously in WAAM that as the heat input increases, the EWW increases and the LH decreases so the effect of \% EP on wall geometry can be explained by the change in heat input [5]. Previous studies on the effect of positive polarity time on ACTIG welding of aluminium indicates that above $20 \% \mathrm{EP}$, electrons are emitted mainly by field effect whereas below this threshold thermionic emission is the main driver of electrons which could explain the fall and rise in the voltage below and above $20 \% \mathrm{EP}[12,20]$. The authors also explained that in the \% EP cycle, the oxide is removed when the arc concentrates on the cathode spot of the thin oxide film. After the oxide is removed, the spot rapidly moves to a new spot and the process repeats itself. Moreover, 
higher \% EP generates more cathode spots with longer arc concentration time which also leads to higher heat input and the resulting increase in fusion area [8]. From this study, surface waviness has also been shown to be approximately constant in the linear walls produced with \% EP ranging between $10 \%$ EP and $40 \%$ EP (Figure 6c). It was found that the surface waviness was about $0.1 \mathrm{~mm}$ indicating the minimum machining requirement during actual production. Conversely, the slightly higher surface waviness in $50 \% \mathrm{EP}$ could be attributed to the arc instabilities resulting from the increased electrode wear rate. This could cause disturbances in the weld pool during deposition. According to Syed et al. [21], when the weld pool is disturbed, it is likely to show increased surface waviness and vice versa. Furthermore, the study has also shown that for a given \% EP, frequency does not have any significant effect on WAAM wall dimensions (Figure 7a).

A further experimental technique of adjusting the heat input of $20 \% E P$ to produce similar weld bead geometry to that of $50 \% \mathrm{EP}$ was conducted by adjusting either the arc length (distance from the tip of electrode to the substrate) to change the voltage or by adjusting the current from the power source. From this study, it is apparent that the controlling factor for weld bead geometry is the heat input as illustrated in Table 3. Therefore increasing the heat input in $20 \% \mathrm{EP}$ increased the bead width with a corresponding decrease in layer height.

Table 3: Effect of balancing the heat input of $20 \% E P$ to that of $50 \% E P$, (WFS $=1.6 \mathrm{~m} / \mathrm{min}$, $\mathrm{TS}=0.15 \mathrm{~m} / \mathrm{min})$

\begin{tabular}{llllllll}
\hline Trial & \% EP & Current (I) & $\begin{array}{l}\text { Voltage } \\
(\mathrm{V})\end{array}$ & $\begin{array}{l}\text { Arc Length } \\
(\mathbf{m m})\end{array}$ & HI (J/mm) & $\begin{array}{l}\text { EWW } \\
(\mathbf{m m})\end{array}$ & LH (mm) \\
\hline A & $20 \% \mathrm{EP}$ & 208 & 13.5 & 5 & 674 & 7.2 & 2.0 \\
\hline B & 50 \%EP & 208 & 16.4 & 5 & 819 & 11.1 & 1.4 \\
\hline C & $20 \% \mathrm{EP}$ & 208 & 15.2 & 7 & 759 & 9.5 & 1.5 \\
\hline D & $20 \% \mathrm{EP}$ & 250 & 13.9 & 5 & 834 & 11.4 & 1.3 \\
\hline
\end{tabular}

In addition, it is also noteworthy that the wear of electrodes resulting from the increase in \% EP could potentially affect the arc length; thus the voltage and the resultant heat input.

\subsection{Microstructure and Porosity}

From microstructural analysis (Figure 9), it was found that increasing \% EP to $50 \%$ led to an increase in the grain size with a resultant decrease in number as compared to $20 \% E P$. The resulting increase in grain size may have been due to the corresponding increase in heat input (Figure 8b). This is expected since increasing the heat input slows down the cooling rate thereby allowing grains more time to grow $[7,22]$. 
For porosity analysis (Figure 10), $50 \%$ EP had a significant amount of pores in comparison to that of $20 \% E P$. Porosity in aluminium based alloys is dependent on the amount of hydrogen dissolved in the liquid phase and results from the large solubility difference between the liquid and solid phases [10]. Previous studies by Cong et al. [7] on the effect of cold metal transfer process on porosity of additively manufactured walls identified a close relationship between grain size and porosity. The authors found that fine grains reduced the tendency for pore formation due to the competition between heterogeneous nucleation of grains and pore nucleation sites prior to solidification. This could explain the low porosity found in $20 \% \mathrm{EP}$ which had finer grain structure as compared to $50 \%$ EP. In addition, the increase in pore numbers and sizes in the initial layers can also be attributed to the slightly high cooling rate of the substrate. This may result in entrapping hydrogen bubbles as they try to escape before solidification of the melt.

\subsection{Mechanical test}

From mechanical test results (Figure 11), no significant differences where seen in 20 $\%$ EP and $50 \%$ EP linear walls built. This indicates that for the same set of parameters, the difference in \% EP does not affect the mechanical properties. Al 5556, a magnesium based alloy, obtains its strength by solid solution strengthening and varies in mechanical properties when there is a change in the chemical composition [6]. During welding, magnesium easily evaporates at high temperature due to their low melting point and vapour pressure in comparison to aluminium [22]. From the study conducted, it can be inferred that the difference in heat input of $20 \%$ EP and $50 \%$ EP may not be critical to affect the chemical composition of the walls deposited. SEM images of the fracture surface of $20 \% E P$ and $50 \% E P$ have been shown in Figure 12. The fracture surface of both walls were mainly characterised by dimples. This indicates that both walls exhibited ductile fracture features [11].

\section{Conclusions}

The effect of TIG alternating current time cycle has been investigated on aluminium WAAM. The following conclusions could be drawn:

- Minimum cleaning for ACTIG process ranged between $10 \%$ EP and $20 \%$ EP.

- The effective wall width is minimum at $20 \% E P$ with a corresponding maximum in layer height. Increasing \% EP between $10 \%$ EP and $40 \%$ EP does not have a significant effect on surface waviness.

- The main controlling factor for wall dimension is the heat input. Increasing \% EP increases the voltage which in turn increases the heat input.

- Increasing the \% EP increases the electrode wear rate.

- Increasing the \% EP does not have any significant effect on mechanical properties (UTS, 0.2 PS and \% elongation).

- For a constant \% EP, frequency does not have any significant effect on WAAM wall dimensions and hardness.

- Increasing the \% EP increases grain sizes and decreases the grain number. 
- Increasing \% EP increases pore sizes and number.

Therefore, optimum condition for ACTIG WAAM of AA 5556 is the electrode positive time cycle of $20 \%$ EP.

\section{Acknowledgement}

The authors would like to thank all the WAAMmat program members for their support.

\section{References}

[1] S.W. Williams, F. Martina, a. C. Addison, J. Ding, G. Pardal, P. Colegrove, Wire+Arc Additive Manufacturing, Mater. Sci. Technol. 32 (2015) 641-647. doi:10.1179/1743284715Y.0000000073.

[2] F. Wang, S. Williams, M. Rush, Morphology investigation on direct current pulsed gas tungsten arc welded additive layer manufactured Ti6Al4V alloy, Int. J. Adv. Manuf. Technol. 57 (2011) 597-603. doi:10.1007/s00170-011-3299-1.

[3] R. Consultants Berger, Additive manufacturing A game changer for the manufacturing industry?, (2013) 1-33.

https://www.rolandberger.com/publications/publication_pdf/roland_berger_additive_m anufacturing_1.pdf.

[4] F. Martina, J. Mehnen, S.W. Williams, P. Colegrove, F. Wang, Investigation of the benefits of plasma deposition for the additive layer manufacture of Ti-6Al-4V, J. Mater. Process. Technol. 212 (2012) 1377-1386.

doi:10.1016/j.jmatprotec.2012.02.002.

[5] P. Almeida, Process Control and Development in Wire and Arc Additive Manufacturing, Cranfield University, Bedfordshire, UK, 2012.

[6] G. Mathers, The Welding of Aluminium and its Alloys, 2002. doi:10.1533/9781855737631.1.

[7] B. Cong, J. Ding, S. Williams, Effect of arc mode in cold metal transfer process on porosity of additively manufactured Al-6.3\%Cu alloy, Int. J. Adv. Manuf. Technol. 76 (2014) 1593-1606. doi:10.1007/s00170-014-6346-x.

[8] M.A.R. Yarmuch, B.M. Patchett, Variable AC Polarity GTAW Fusion Behavior in 5083 Aluminum, Weld. Res. 86 (2007) 196-200. https://app.aws.org/wj/supplement/wj0707196.pdf.

[9] K.F. Ayarkwa, S. Williams, J. Ding, Investigation of pulse advance cold metal transfer on aluminium wire arc additive manufacturing, Int. J. Rapid Manuf. 5 (2015) 44-57.

[10] J. Gu, J. Ding, S.W. Williams, H. Gu, P. Ma, Y. Zhai, The effect of inter-layer cold working and post-deposition heat treatment on porosity in additively manufactured aluminum alloys, J. Mater. Process. Technol. 230 (2016) 26-34. doi:10.1016/j.jmatprotec.2015.11.006.

[11] J. Gu, J. Ding, H. Gu, J. Bai, Y. Zhai, P. Ma, The strengthening effect of inter-layer cold working and post-deposition heat treatment on the additively manufactured Al6.3Cu alloy, Mater. Sci. Eng. A. 651 (2016) 18-26.

[12] L.M. Cirino, J.C. Dutra, The influence of positive polarity time on GTAW AC of 
aluminium, Weld. Int. 24 (2010) 825-833. doi:10.1080/09507110903568919.

[13] J. Cho, J.-J. Lee, S.-H. Bae, Heat input analysis of variable polarity arc welding of aluminum, Int. J. Adv. Manuf. Technol. 81 (2015) 1273-1280. doi:10.1007/s00170015-7292-y.

[14] R. Sarrafi, R. Kovacevic, Cathodic Cleaning of Oxides from Aluminum Surface by Variable-Polarity Arc, Weld. J. 89 (2010) 1S-10S.

[15] M. Yarmuch, J. Pepin, B. A.C., Patchet B.M., Characterisation of fusion behaviour during variable polarity ac welding of aluminium, in: Trends Weld. Res. Proc. 9th Int. Conf., 2013: pp. 129-137.

[16] Weman Klas, Welding processes handbook, Second Edi, Woodhead Publishing Limited, Cambridge, UK, 2012.

[17] H. Wang, W. Jiang, J. Ouyang, R. Kovacevic, Rapid prototyping of 4043 Al-alloy parts by VP-GTAW, J. Mater. Process. Technol. 148 (2004) 93-102. doi:10.1016/j.jmatprotec.2004.01.058.

[18] L.Y. Bai, S.B. Lin, S.B. Dong, C.L. Fan, Mechanical properties of 2219-Al components produced by additive manufacturing with TIG, Int J Adv Manuf Technol. 86 (2016) 479-485. https://www.researchgate.net/profile/Sanbao_Lin/publication/299518465_Molten_pool _behaviors_and_weld_forming_characteristics_of_allposition_tandem_narrow_gap_GMAW/links/58992631aca2721f0daf42ca/Molten-poolbehaviors-and-weld-forming-characteristics-of-al (accessed July 6, 2017).

[19] J.N. DuPont, a. R. Marder, Thermal Efficiency of Arc Welding Processes, Weld. Res. Suppl. (1995) 406-416.

[20] P.W. Fuerschbach, Cathodic cleaning and heat input in variable polarity plasma arc welding of aluminum, Weld. J. (Miami, Fla). 77 (1998) 76-s.

http://www.scopus.com/inward/record.url?eid=2-s2.00031999969\&partnerID=40\&md5=ab9619a0db45a393544e3551b352a063.

[21] W.U.H. Syed, A.J. Pinkerton, L. Li, Simultaneous wire- and powder-feed direct metal deposition: An investigation of the process characteristics and comparison with singlefeed methods, J. Laser Appl. 18 (2006) 65-72. doi:10.2351/1.2164485.

[22] D. Min, J. Shen, S. Lai, J. Chen, Effect of heat input on the microstructure and mechanical properties of tungsten inert gas arc butt-welded AZ61 magnesium alloy plates, Mater. Charact. 60 (2009) 1583-1590. doi:10.1016/j.matchar.2009.09.010. 
2017-10-09

\title{
Assessing the effect of TIG alternating current time cycle on aluminium wire + arc additive manufacture
}

\author{
Ayarkwa, Kwasi
}

Elsevier

Ayarkwa KF, Williams SW, Ding J, Assessing the effect of TIG alternating current time cycle on aluminium wire+ arc additive manufacture, Additive Manufacturing, Volume 18, December 2017, pp. 186-193

http://dx.doi.org/10.1016/j.addma.2017.10.005

Downloaded from Cranfield Library Services E-Repository 